\title{
Evasão escolar no Ensino Secundário em Quebec (Canadá) ${ }^{1}$
}

Sandra Maria Glória da Silva* Pierre Canisius Kamanzi**

* (Universidade de São Paulo, São Paulo, Brasil).

** (Université de Montréal, Quebec, Canadá).
Resumo: Entre as províncias canadenses, Quebec possui a taxa mais alta de jovens não diplomados no secundário, $11,5 \%$ em 2016. A pesquisa realizada visou: a) examinar o perfil desses jovens e mapear os motivos pelos quais eles não concluíram os estudos; b) analisar em que medida os programas governamentais implantados para prevenir e combater a evasão escolar são eficazes e equitativos. Realizou-se pesquisa bibliográfica nas bases de dados Scopus, Eric e Érudit. Foram consultadas ainda publicações oficiais do governo de Quebec. Notou-se que evasão é maior: entre homens que entre mulheres, na rede pública de ensino $(18,4 \%)$ que na rede privada $(7,6 \%)$. Nas escolas em reservas indígenas ela chega a $81,3 \%$. A baixa escolaridade dos pais está entre as principais causas de evasão.

Palavras-chave: Evasão escolar em Quebec. Jovens e adultos. Ensino Secundário.

Este artigo origina-se de pesquisa realizada durante doutorado sanduíche na Université de Montréal, no segundo semestre de 2017, sob supervisão do prof. Pierre Canisius Kamanzi, Ph.D., e financiada pelo Fonds de Recherche du Québec - Nature et Technologies. Agradecemos à Carmen Sylvia Vidigal Moraes e Abelardo Bento Araújo pela leitura e pertinentes sugestões. 
A evasão escolar no Ensino Secundário é um problema que atinge diversos países e preocupa seus governantes devido às consequências econômicas, sociais e pessoais que ocasiona. O termo "evasão" é uma metáfora importada do jargão militar e remete ao "ato de se desprender”, ou seja, "separar algo que estava preso, romper o contato, se retirar”. No domínio militar significa "movimento de recuo, abandono do combate, retirada diante da pressão do inimigo” (ROBERT; REY-DEBOVE; REY, 2012, p. 641).

Nos Estados Unidos, no fim do século XIX, alguns autores utilizavam o termo drop out para designar o abandono dos estudos pelos alunos. 0 uso dessa concepção remete ao ato de o aluno se desinteressar parcial ou totalmente do dever e da obrigação de se escolarizar até certo nível considerado, formal ou informalmente, obrigatório e durante um período determinado pelo Estado. Com efeito, vários países instituíram escolarização gratuita e obrigatória para todos os jovens. A duração e o nível, no entanto, variam entre países de acordo com os objetivos das políticas públicas em educação e os contextos socioeconômicos (UNESCO, 2000a, 2000b).

$\mathrm{Na}$ maior parte dos países industrializados e dos emergentes, essa escolarização obrigatória cobre o Ensino Primário e o Secundário (equivalente à Educação Básica no Brasil). Já nos países em desenvolvimento, ela se restringe ao Primário. Por trás desse caráter obrigatório se encontra a vontade política de munir cada jovem de uma formação de base, bem como adquirir valores, saberes e conhecimentos essenciais para se integrar na sociedade e, mais particularmente, no mercado de trabalho. Nos países industrializados, ter um diploma de estudos secundários ou ao menos uma qualificação profissional revela-se como o mínimo para ter um lugar na sociedade (QUÉBEC, 2002a; MÉNARD, 2009).

Importante ressaltar a diferença entre fracasso, evasão e abandono escolar. “Em Quebec, um evadido é um jovem que deixa de frequentar a escola sem ser detentor de um diploma de estudos secundários. Quando essa infrequência à escola se estende por um período de 5 anos, fala-se então de abandono escolar" (BARRIAULT, 2016, p. 3). O fracasso escolar significa estar em dificuldade, ou seja, ter baixo desempenho nos estudos e não atingir os objetivos propostos. Consequentemente, os alunos que sofrem sucessivos fracassos podem evadir e, em seguida, abandonar a escola (POTVIN, 2015; LECLERCK, POTVIN; MASSÉ, 2016). 
No Brasil, a distinção entre evasão e abandono escolar ainda é tema de discussões e análises (SILVA FILHO; ARAÚJO, 2017). O ponto consensual é que o fenômeno existe e requer solução. Entre os anos de 2014 e 2015, a evasão em todas as séries do Ensino Médio chegou a 11,2\%. Essa taxa foi mais alta nas escolas rurais (12\%) que nas urbanas $(11,1 \%)$ e na rede municipal $(9,8 \%)$ que nas redes federal (5,9\%) e privada (3,8\%) (BRASIL, 2017). De acordo com a Pesquisa Nacional por Amostra de Domicílios Contínua, em 2017, no Brasil, 11,5 milhões de pessoas (7,0\%) com 15 anos ou mais eram analfabetas, $33,8 \%$ da população com idade acima de 25 anos não concluiu o Ensino Fundamental e $26,8 \%$ dos brasileiros nessa mesma faixa etária possuíam o Ensino Médio completo como escolaridade mais elevada (INSTITUTO BRASILEIRO DE GEOGRAFIA E ESTATÍSTICA, 2017).

Entende-se que a história, a cultura, a conjuntura, a natureza dos problemas são singulares em cada país. Por isso, o estudo que aqui se apresenta não teve por finalidade transpor modelos entre países, mas suscitar reflexões e vislumbrar possibilidades por meio do conhecimento de experiências exitosas e soluções para desafios comuns. Tem-se por perspectiva teórica os estudos comparados em uma abordagem histórica na qual o objeto é analisado considerando-se tanto o contexto no qual se originou - e que lhe confere significado - como as relações culturais e particularidades históricas que o determinam (FRANCO, 2000).

Os canadenses, de modo geral, valorizam muito a educação, mas, por diversos fatores, alguns entre eles não conseguem concluir o Ensino Secundário apesar de seu caráter obrigatório desde mais de meio século (GILMORE, 2010). Entre as províncias canadenses, Quebec possui a taxa mais alta de jovens não diplomados nesse nível de ensino, 11,5\% em 2016 (UPPAL, 2017). Em seguida, estão as províncias de Manitoba e Alberta. Por outro lado, aquelas que possuem os índices mais elevados de alunos que concluíram o secundário são Nouveau-Brunswick e Saskatchewan (BUSHNIK, 2003).

Este estudo focaliza esse público e as políticas implantadas para atenuar o problema da evasão escolar e tem por objetivos: a) examinar o perfil desses jovens e mapear os motivos pelos quais eles não concluíram os estudos; b) analisar em que medida os programas governamentais implantados para prevenir e combater a evasão escolar são eficazes e equitativos. 0 período de abrangência da pesquisa foi delimitado em função do ano de implantação do Programme de formation de l'école québécoise (2001) e do programa l’École, j’y tiens! (2009). 
Realizou-se pesquisa bibliográfica temática a partir das bases de dados Scopus, Eric e Érudit, bem como no Google Scholar utilizando os termos evasão escolar de jovens e adultos. Publicações oficiais disponibilizadas pelo Ministère de l'Éducation, du Loisir et du Sport [Ministério da Educação, do Lazer e do Esporte de Quebec] (Mels), Ministère de l'éducation et de l'enseignement supérieur [Ministério da Educação e do Ensino Superior de Quebec] (Mees), Statistique Canada [Estatística Canadá] e l'Institut de la statistique du Québec [Instituto de Estatística de Quebec] foram consultadas.

Tendo-se em vista que a educação comparada propicia, entre outros aspectos, ampliar as possibilidades de aperfeiçoamento de um sistema educativo por meio da análise de experiências internacionais (GOROSTIAGA, 2013), esperase que o estudo de políticas de prevenção e combate à evasão escolar no Ensino Secundário em Quebec (Canadá) possa suscitar reflexões e iluminar possibilidades para a educação brasileira, tais como: identificar o perfil de jovens e adultos que possuem maior risco de evasão; compreender as razões pelas quais esses jovens e adultos se evadem; atuar na prevenção da evasão escolar junto a esses jovens e adultos; desenvolver estratégias visando o retorno de jovens e adultos à educação formal com vistas à conclusão da Educação Básica e à inserção profissional.

O texto está dividido em quatro seções após a introdução. Na primeira, apresenta-se o sistema educacional de Quebec. Na segunda, são expostos dados sobre jovens e adultos sem diploma de Ensino Secundário. Na terceira, confere-se relevo às principais causas de evasão escolar, segundo a bibliografia consultada. Na quarta, abordam-se políticas de prevenção e combate à evasão escolar e programas em favor da permanência e do sucesso escolar de jovens e adultos implantados pelo governo de Quebec a partir de 2001.

\section{Sistema educacional de QuebeC}

No Canadá, cada província e território tem seu próprio ministério da educação e não há um ministério federal. O Ministério da Educação de Quebec foi criado em 1964 e desde então passou por mudanças e teve outras denominações. 0 sistema de educação em Quebec possui quatro níveis de ensino: o Primário incluindo-se a pré-escola, o Secundário, o Colegial e o Universitário. Apenas o Primário e o Secundário são obrigatórios para estudantes com idade entre 6 e 16 anos (QUÉBEC, 2006a). 
O Ensino Secundário tem a duração de cinco anos e está organizado em dois ciclos. 0 primeiro dura três anos e visa consolidar conhecimentos adquiridos no Primário e iniciar a orientação profissional; o segundo oferece disciplinas optativas voltadas à formação geral e programas de formação profissional. Os estudantes ingressam nesse nível de ensino aos 12 anos de idade e, após concluí-lo, recebem um diploma de estudos secundários (DES). De acordo com o percurso formativo realizado pelo discente, ele poderá obter ainda certificados e diplomas de formação profissional (QUÉBEC, 2006a).

Figura 1 - Sistema escolar em Quebec

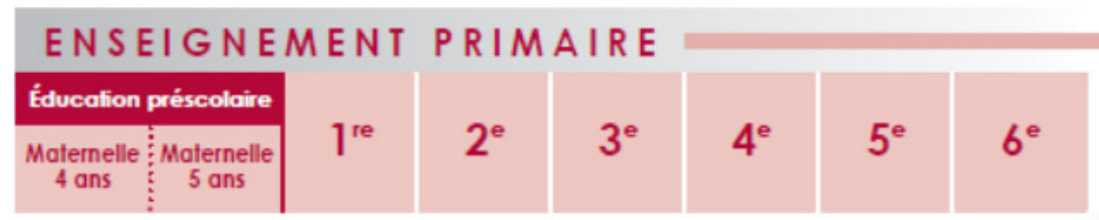

ENSEIGNEMENT SECONDAIRE
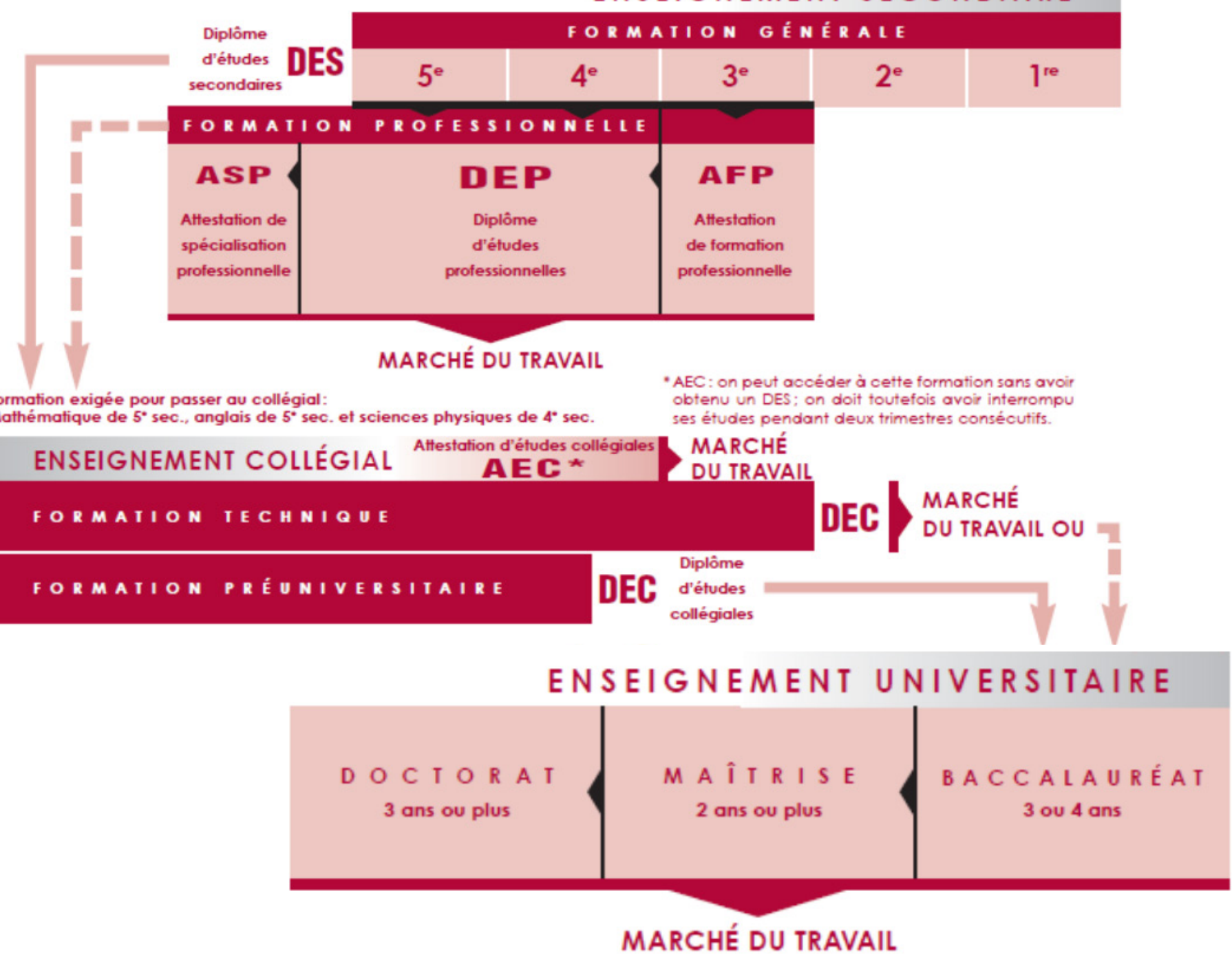

Q Tous droits réservés: Jobboom inc.

L'ÉDUCATION AU QUÉBEC • EN BREF

Fonte: Québec (2006a, p. 4). 
Para ingressar no Ensino Colegial é necessário ter um DES e para cursar o Ensino Superior é preciso ter um diploma de estudos colegiais (DEC). Os Collèges d'enseignement general et professionnel (Cégeps) são uma particularidade de Quebec e oferecem programas de formação pré-universitária, formação técnica de nível superior (cursos tecnológicos) e cursos de qualificação profissional. Os cursos de formação técnica priorizam o ingresso no mercado de trabalho e possibilitam o acesso ao Ensino Superior de forma restrita em comparação com os cursos pré-universitários.

A Formação Geral de Adultos (FGA) em Quebec é uma modalidade de ensino estruturada, juridicamente definida e financiada com recursos públicos. Os serviços educativos destinados aos adultos são estabelecidos pelo Regime Pedagógico da Formação Geral de Adultos, o qual é regulamentado pela lei

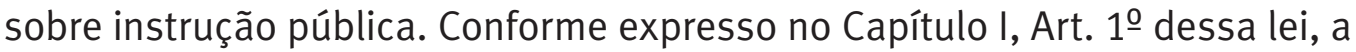
FGA oferece formação, educação popular e serviços complementares, e tem por objetivos:

\begin{abstract}
Permitir ao adulto ampliar sua autonomia; facilitar sua inclusão social e profissional; favorecer sua inserção e permanência no mercado de trabalho; possibilitar que ele contribua para o desenvolvimento econômico, social e cultural do meio onde vive; propiciar a aquisição de uma formação sancionada pelo ministro [formação de base prevista em lei] (QUÉBEC, 2017).
\end{abstract}

Desde os anos 1990, Doray e Bélanger (2014, p. 216) constatam uma “situação de concorrência entre diferentes políticas públicas para acesso a recursos públicos destinados à educação". Gradualmente, surge uma tensão entre políticas de educação de adultos e políticas de combate à evasão escolar e em favor da "diplomação de jovens em dificuldade nas escolas consideradas clássicas” (DORAY; BÉLANGER, 2014, p. 216, grifo do autor).

Em Quebec, a Formação Geral de Adultos vivencia, desde a sua criação, uma tensão entre a oferta de formação de base, norteada pelo desenvolvimento contínuo do potencial humano, e uma formação que responda às necessidades do setor produtivo. Entretanto, a preparação para o mercado de trabalho predomina, especialmente desde os anos 1990, quando as políticas de educação de adultos foram significativamente orientadas pela resposta às exigências da globalização. Essas exigências se traduzem por uma demanda cada vez maior de competências profissionais, adaptação às rápidas mudanças tecnológicas, às transformações sociais, culturais e do mercado de trabalho (QUÉBEC, 2007a). 
Em relação ao conjunto de políticas educativas, a educação de adultos ocupa lugar marginal, sobretudo em comparação às políticas de formação inicial de jovens. Ela é submetida a cortes orçamentários que limitam seu desenvolvimento ${ }^{2}$, reduzem os serviços ofertados e têm impactos negativos sobre a aprendizagem dos alunos. As políticas de Formação Geral de Adultos são sempre restritas à alfabetização e letramento ou à adequação entre formação e trabalho (INSTITUT DE COOPÉRATION POUR L'ÉDUCATION DES ADULTES - ICEA, 2016a, 2016b).

Desde o planejamento estratégico 2016-2021, o Icea recomenda combater a marginalização da educação de adultos, valorizar essa modalidade de ensino e favorecer a participação de pessoas excluídas ou em risco de exclusão social nos diferentes espaços de aprendizagem (escolas, centros comunitários e associações).

\section{Abandono e eVAsão escolar no Ensino SeCundário}

Segundo pesquisa realizada em 2002 pela Ad hoc Recherche, somente 5\% dos cidadãos quebequenses entrevistados declararam que a educação deveria encabeçar a lista de prioridades governamentais. Por outro lado, $52 \%$ consideram que a saúde deveria estar em primeiro lugar. Esses resultados poderiam ser explicados pelo envelhecimento da população e pelo consequente aumento na demanda por serviços de saúde. Entretanto, eles divergem daqueles observados no restante do Canadá, como mostra o Gráfico 1, a seguir.

Em 2017, o governo do Canadá reduziu o financiamento da alfabetização de adultos e deixou inúmeras instituições em situação dramática. Sem recursos, elas foram obrigadas a interromper os serviços e fechar as portas. Essa redução no financiamento "de organismos e redes de alfabetização, em escala nacional ou provincial, tem por consequência direta desmantelar uma infraestrutura fundamental para a alfabetização” (BARIL, 2017, p. 1). 
Gráfico 1 - A educação é menos valorizada em Quebec que no restante do Canadá

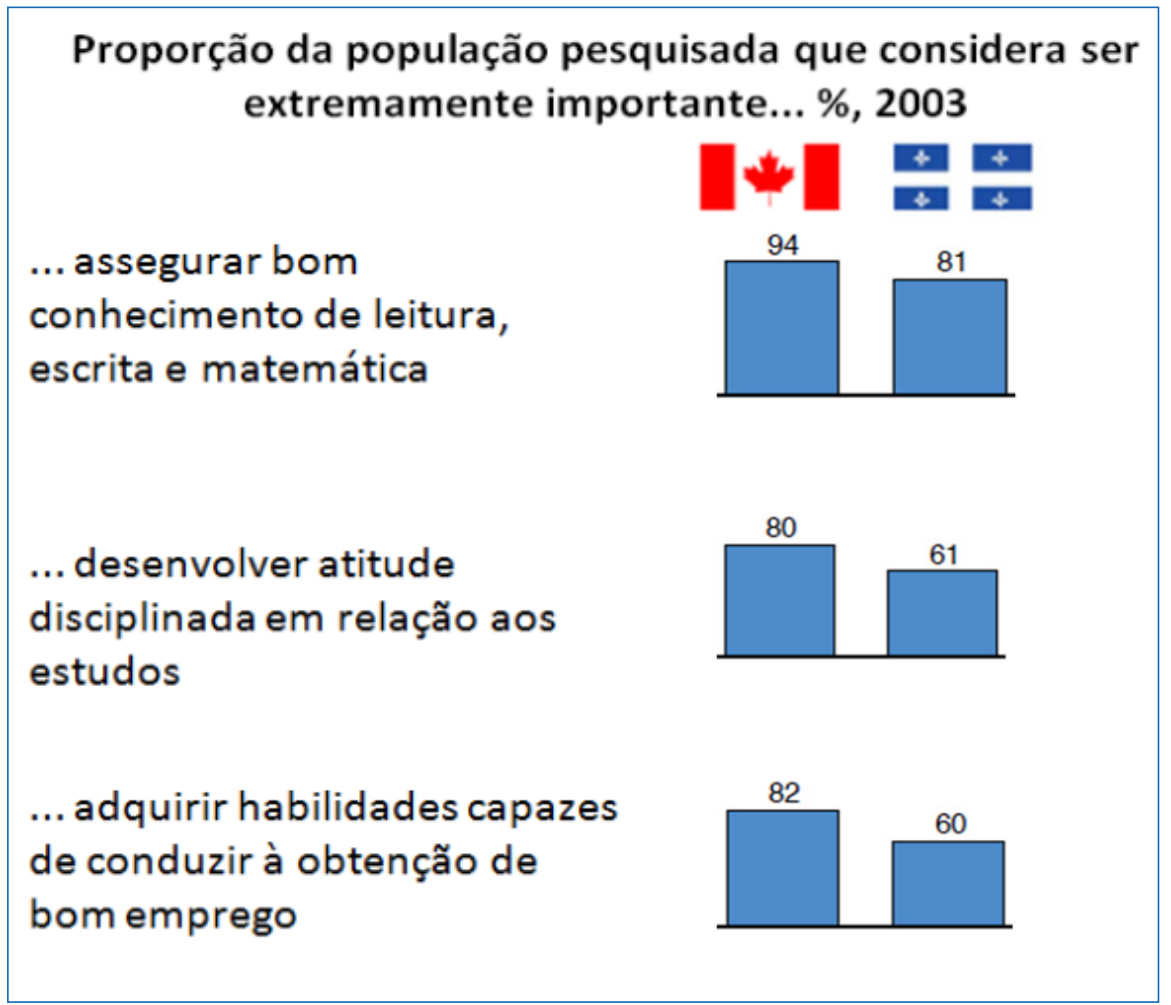

Fonte: Adaptado de Ménard (2009, p. 15).

Em Quebec, a taxa anual de evasão na formação geral de jovens foi de $13,5 \%$ em 2014-2015, dos quais 16,8\% foram entre meninos e 10,4\% entre meninas (QUÉBEC, 2016). No período de 1999-2000 a 2014-2015, essa taxa teve uma queda de $8,4 \%$. 
Gráfico 2 - Taxa de evasão anual no secundário, em Quebec, 1999-2015

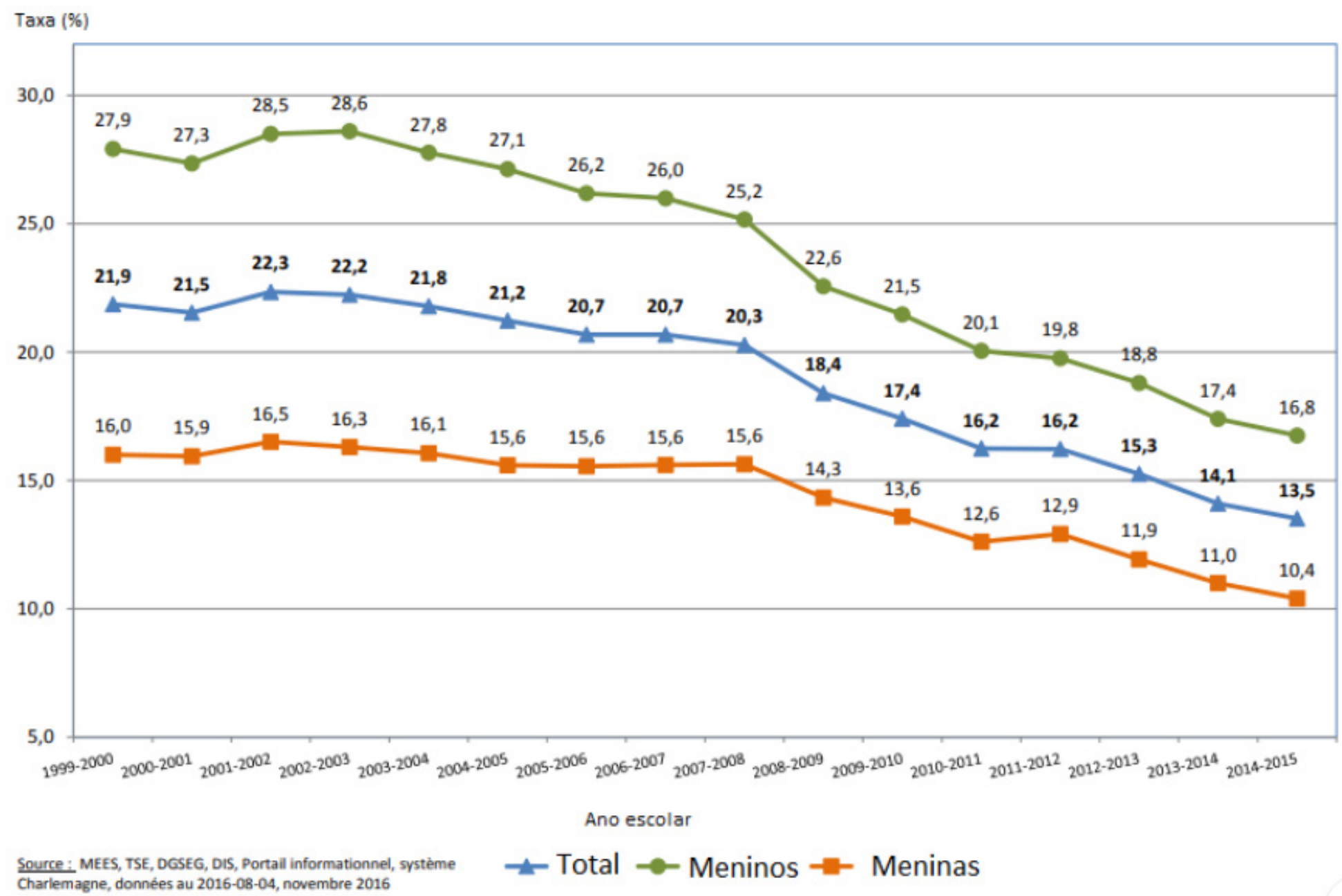

Fonte: Adaptado de Québec (2016).

Em 2016, havia no Canadá 2.292.760 homens com idade entre 25 e 34 anos (STATISTIQUE CANADA, 2017), dos quais 8,5\% não possuíam diploma de Ensino Secundário. Entre as 2.322.625 mulheres nessa mesma faixa etária, 5,4\% não eram diplomadas nesse nível de ensino (UPPAL, 2017). Ao desagregar esses dados, constata-se que essa taxa varia conforme os grupos sociais e é mais expressiva entre os autóctones, como se pode visualizar na Tabela 1, a seguir. Em comparação com o restante do Canadá, Quebec detém a taxa de evasão mais elevada entre alunos do sexo masculino, 11,5\%. 
Tabela 1 - Jovens de 25 a 34 anos sem diploma de ensino secundário, 2016

\begin{tabular}{|l|c|c|}
\hline \multicolumn{2}{|l|}{ Homens \% } & Mulheres \% \\
\hline Não autóctones nascidos no Canadá & 8,5 & 4,9 \\
\hline Autóctone & 20,1 & 15,9 \\
\hline Imigrantes & 6,5 & 5,3 \\
\hline \multicolumn{2}{|l|}{ Todos (Em todo o Canadá) } & 8,5 \\
\hline \multicolumn{2}{|l|}{} & \\
\hline Por província & 8,2 & 3,5 \\
\hline Terre-Neuve-et-Labrador & 6,2 & 4,1 \\
\hline Île-du-Prince-Édouard & 7,3 & 4,5 \\
\hline Nouvelle-Écosse & 7,4 & 3,8 \\
\hline Nouveau-Brunswick & 11,5 & 6,2 \\
\hline Québec & 7,6 & 5,1 \\
\hline Ontario & 9,4 & 6,3 \\
\hline Manitoba & 8,9 & 6,7 \\
\hline Saskatchewan & 8,2 & 5,9 \\
\hline Alberta & 6,2 & 4,5 \\
\hline Colombie-Britannique & & \\
\hline
\end{tabular}

Fonte: Adaptado de Uppal (2017, p. 4).

Os evadidos não formam um grupo homogêneo, mas em Quebec eles são, em sua maioria, do sexo masculino; apresentam atraso em relação a idade/ série; possuem algum tipo de deficiência, dificuldade de adaptação ou de aprendizagem; são imigrantes, frequentemente de primeira geração ${ }^{3}$; residem em regiões distantes dos grandes centros ou em áreas rurais (JANOSZ, 2000; GILMORE, 2010; QUÉBEC, 2015; BARRIAULT, 2016).

Os jovens adultos ${ }^{4}$ que vivem em regiões distantes possuem menor escolaridade em relação àqueles que residem em áreas urbanas (BARRIAULT, 2016; GILMORE, 2010). Os alunos com maior risco de não concluir os estudos secundários são “jovens do sexo masculino, de Quebec e de algumas províncias na região oeste" (GILMORE, 2010, p. 1). A proporção de pessoas não diplomadas no secundário, em regiões distantes dos centros urbanos, é de $20 \%$, ou seja, um a cada cinco habitantes (BARRIAULT, 2016).

Consideram-se alunos imigrantes de primeira geração aqueles nascidos fora do Canadá. Os de segunda geração são os que nasceram no Canadá e ao menos um dos pais nasceu no exterior desse país.

4 O termo 'jovem adulto’ é utilizado tanto pelos autores da bibliografia consultada como pelo Ministério da Educação, do Lazer e do Esporte de Quebec para se referir a pessoas entre 17 e 24 anos em situação de evasão escolar. 
Os autores concordam que há vários fatores associados à evasão escolar (JANOSZ, 2000), tais como o nível de défavorisation (desvantagem econômica, social e cultural) de algumas escolas secundárias públicas (QUÉBEC, 2015), a origem social do aluno, bem como sua saúde física e mental (PICA; PLANTE; TRAORÉ, 2014). A taxa anual de evasão varia conforme o meio onde a escola se encontra (desfavorecido ou favorecido) e o tipo de rede escolar (pública ou privada). Em 2011-2012, a taxa de evasão em escolas secundárias em meios desfavorecidos chegou a 24,2\%; já nos meios favorecidos ${ }^{5}$, essa taxa foi de $12,2 \%$. Nesse mesmo período, a taxa de evasão foi mais significativa nas escolas da rede pública (18,4\%) que em comparação às escolas da rede privada (7,6\%) (QUÉBEC, 2015).

Além de a taxa de evasão escolar ser mais elevada na rede pública em relação à rede privada, essa taxa é mais alta nas escolas governamentais onde "a maioria dos alunos [...] é instruída dentro de reservas indígenas" (L'OBSERVATOIRE DE L'ADMINISTRATION PUBLIQUE, 2012, p. 2). Em 20132014, a evasão de alunos nessas escolas foi de $81,3 \%$. Nota-se, pela Tabela 2 , que essa taxa é consideravelmente mais alta entre os meninos.

Tabela 2 - Taxa de evasão anual na formação geral de jovens (saídas sem diploma nem qualificação), distribuição por sexo e rede de ensino, 2013-2014

\begin{tabular}{|lc|c|c|} 
& \multicolumn{1}{c}{ Total \% } & Meninos \% & Meninas \% \\
\hline Em toda a província Quebec & 14,1 & 17,4 & 11,0 \\
\hline Rede pública (72 Comissões Escolares) & 16,2 & 19,8 & 12,6 \\
\hline Estabelecimentos privados de ensino & 6,6 & 7,9 & 5,5 \\
\hline Escolas governamentais & 81,3 & 87,1 & 74,7 \\
\hline
\end{tabular}

Fonte: Adaptado de Québec (2015c).

Denomina-se "meio menos favorecido" aquele que possui baixo índice de milieu socioéconomique (IMSE), o qual é composto por variáveis consideradas como as que mais determinam o fracasso escolar - a baixa escolaridade da mãe e o desemprego dos pais. Esse índice é calculado a partir de dados do recenseamento canadense de famílias com filhos menores de 18 anos. "O IMSE de um aluno corresponde àquele da unidade populacional de onde ele provém, enquanto o da escola corresponde à média de todos os IMSE dos alunos" (QUÉBEC, 2018, p. 1). 


\section{Causas de evasão escolar no Ensino Secundário em Quebec}

As causas de evasão escolar são variadas e resultam de uma combinação de diversos fatores, sociais e individuais, que se interagem (POTVIN, 2015). Entre esses fatores estão dificuldades pessoais, familiares, escolares (BARRIAULT, 2016), inerentes a problemas socioeconômicos, os quais podem se articular às "frustrações ocasionadas pelos fracassos escolares e por dificuldades na relação com os pares, os professores e os pais” (LECLERCK; POTVIN; MASSÉ, 2016, p. 115). Entre as jovens, a gravidez e a educação dos filhos são "fatores que determinam sua decisão de se evadir e esses possuem peso maior quando conjugados com problemas decorrentes da pobreza" (BARRIAULT, 2016, p. 6).

Durante muito tempo, os estudiosos do fracasso escolar conferiram relevo ao aluno, sua família e à escola. Gilles, Christinat e Delévaux (2012) constataram que nos anos 1980-1990 houve importante mudança de paradigma na abordagem e compreensão desse fenômeno. Segundo essa perspectiva,

o indivíduo é doravante considerado dentro de sua identidade social e não apenas como uma entidade isolada, única e solitária. [Consequentemente,] o sucesso ou o fracasso não são mais unicamente atribuídos ao trabalho do aluno e a sua perseverança, mas também a sua origem social (GILLES; CHRISTINAT; DELÉVAUX, 2012, p. 5).

Sob esse mesmo ponto de vista, os estudos sobre abandono escolar realizados por Langevin (1999) indicam que:

O aspecto socioeconômico constitui um dos fatores observados quase constantemente em muitos estudos sobre abandono escolar: os evadidos originam-se frequentemente de famílias desprovidas no plano econômico e cultural. Em Quebec, as crianças cujo pai possui menos que oito anos de escolarização têm três vezes mais risco de abandonarem os estudos que aquelas cujo pai concluiu o secundário (LANGEVIN, 1999, p. 77).

Mesmo que a evasão escolar atinja alunos de todos os meios sociais, ela é mais elevada entre aqueles oriundos de meios socioeconômicos menos favorecidos. Em 2000-2001, essa taxa era de 35,6\%, como expressa o Gráfico 3, a seguir. 
Gráfico 3 - Taxa de evasão segundo o meio socioeconômico (2000-2001)

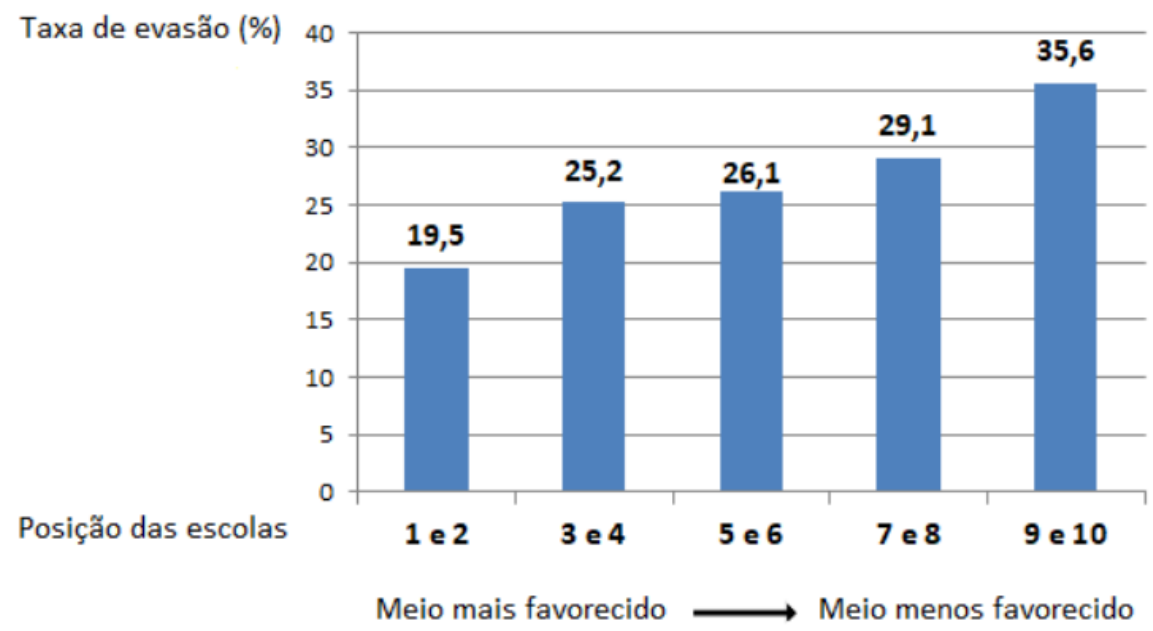

Fonte: Adaptado de Québec (2004a, p. 5).

Considerando-se outros aspectos além do socioeconômico, os alunos que frequentam escolas francófonas têm alto risco de se evadir (QUÉBEC, 2007b). Também estão nesse grupo de risco alunos obesos ou com baixa estima, na faixa etária dos 13 aos 21 anos (PICA; PLANTE; TRAORÉ, 2014). O mesmo ocorre com alunos usuários de substâncias psicoativas. Diferentemente do que se poderia supor, os alunos que trabalham em tempo parcial, em média 20 horas semanais, são menos suscetíveis de evasão (PICA; PLANTE; TRAORÉ, 2014).

Vários fatores de risco associados à evasão escolar foram identificados. No entanto, esse risco é mais elevado entre alunos mais velhos, que apresentam déficit de atenção; transtorno de comportamento (como agressividade, delinquência, gritos, ameaças e mudanças repentinas de humor); depressão; dificuldade em seguir normas disciplinares que prevalecem no ambiente escolar; atitudes negativas em relação à escola e aos professores (BLAYA; FORTIN, 2011; JANOSZ et al., 2013). A evasão escolar é mais recorrente entre alunos autóctones, entre jovens que possuem filhos ou vivem com um cônjuge, entre aqueles cuja língua materna é o francês. O consumo de marijuana, haxixe e álcool é recorrente entre jovens não diplomados (BUSHNIK, 2003).

A pobreza, a estrutura familiar, as atitudes e as práticas dos pais são igualmente consideradas fatores de risco (JANOSZ et al., 2013). Os alunos cujas famílias valorizam pouco a escola, que recebem baixo estímulo em relação à leitura, que residem em bairros caracterizados pela insegurança e pobreza têm potencial para evadir. A obtenção de um diploma não é considerada importante para jovens em situação de evasão escolar, bem 
como para seus pais e amigos. A maioria dos jovens evadidos é de filhos de pais não diplomados no secundário, os quais exercem funções que não exigem nenhum diploma (BUSHNIK, 2003). Segundo pesquisa realizada por Janosz et al. (2013, p. 15), em média "15\% dos alunos de 12 anos nascidos em Quebec no final dos anos 1990 (18\% meninos, 12\% meninas) apresentam sérios riscos de evadirem no secundário". Por isso, eles recomendam priorizar o apoio aos estudantes oriundos de meios desfavorecidos e aos seus pais, porque a família desses alunos tem mais dificuldade de oferecer estrutura e apoio adequados em matéria de escolarização e aprendizagem.

\section{Políticas de PREVEnÇÃo e COMBate À eVASÃo escolar}

A evasão escolar tem consequências pessoais, sociais, profissionais e econômicas (MÉNARD, 2009). Os jovens adultos sem diploma são socialmente mais vulneráveis porque têm longa história de fracasso escolar e criaram uma imagem negativa da escola. Consequentemente, "eles precisam se empenhar mais para vencer e são menos motivados" (MAZALONS; BOURDON, 2015, p. 168). Eles estão predispostos a problemas decorrentes do consumo excessivo de álcool e não têm um meio familiar propício à retomada dos estudos; trabalham em funções pouco valorizadas e têm dificuldade em atender às exigências escolares. Os jovens evadidos têm menos chance de se integrarem social e profissionalmente, por isso são mais suscetíveis a depender de auxílio social e seguro desemprego (JANOSZ, 2000). Além disso, são mais propensos à depressão, à ansiedade e têm expectativa de vida mais curta que os diplomados (MÉNARD, 2009). 0 Gráfico 4 mostra dados de pesquisa realizada em 2008-2009 sobre os efeitos da falta de diploma. 
Gráfico 4 - Os não diplomados são penalizados em diversos aspectos

Rendimento anual médio

Diferença/racio

\section{$40000 \$$}

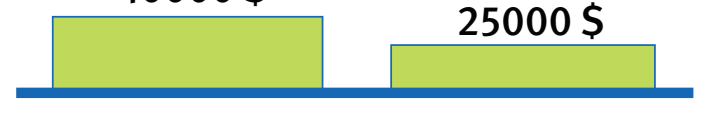

Taxa média de desemprego

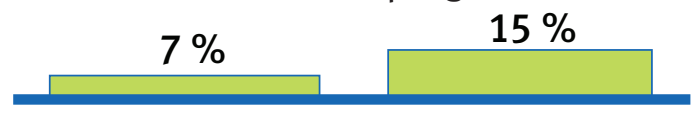

Expectativa média de vida

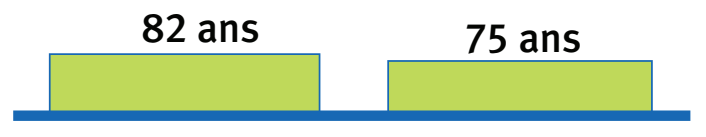

Risco de depressão na idade adulta*

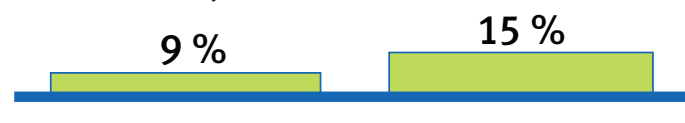

Proporção de população carcerária**

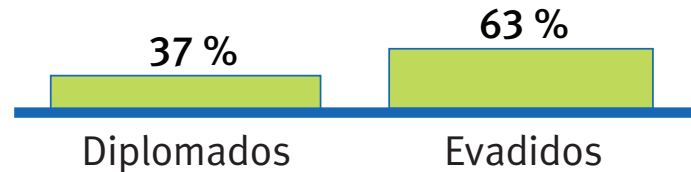

Diplomados

\section{Evadidos}

\section{$15000 \$$}

\section{$2,1 \times$}

\section{7 ans}

\section{$1,7 \times$}

\section{$1,7 x$}

* Dados referentes às mulheres

** Proporção do conjunto de detentos representados em 100\%

Fontes: Statistique Canada; Institut de la statistique du Québec; Health Affairs; ministère de I a Sécurite publique; OCDE; Mckinsey \& Compagnie

Fonte: Adaptado de Ménard (2009, p. 11).

Em uma sociedade onde o conhecimento e as competências em diversas áreas são cada vez mais importantes, pessoas com baixos níveis de escolarização e letramento correm o risco de ser marginalizadas e excluídas socialmente (INSTITUT DE COOPERATION POUR L'EDUCATION DES ADULTES, 2016a). As taxas de emprego de pessoas sem diploma expostas no Gráfico 5 e as demandas de ajuda social ilustram essa situação. 
Gráfico 5 - Taxa de emprego entre jovens adultos sem diploma de estudos secundários em Quebec, 2007-2016

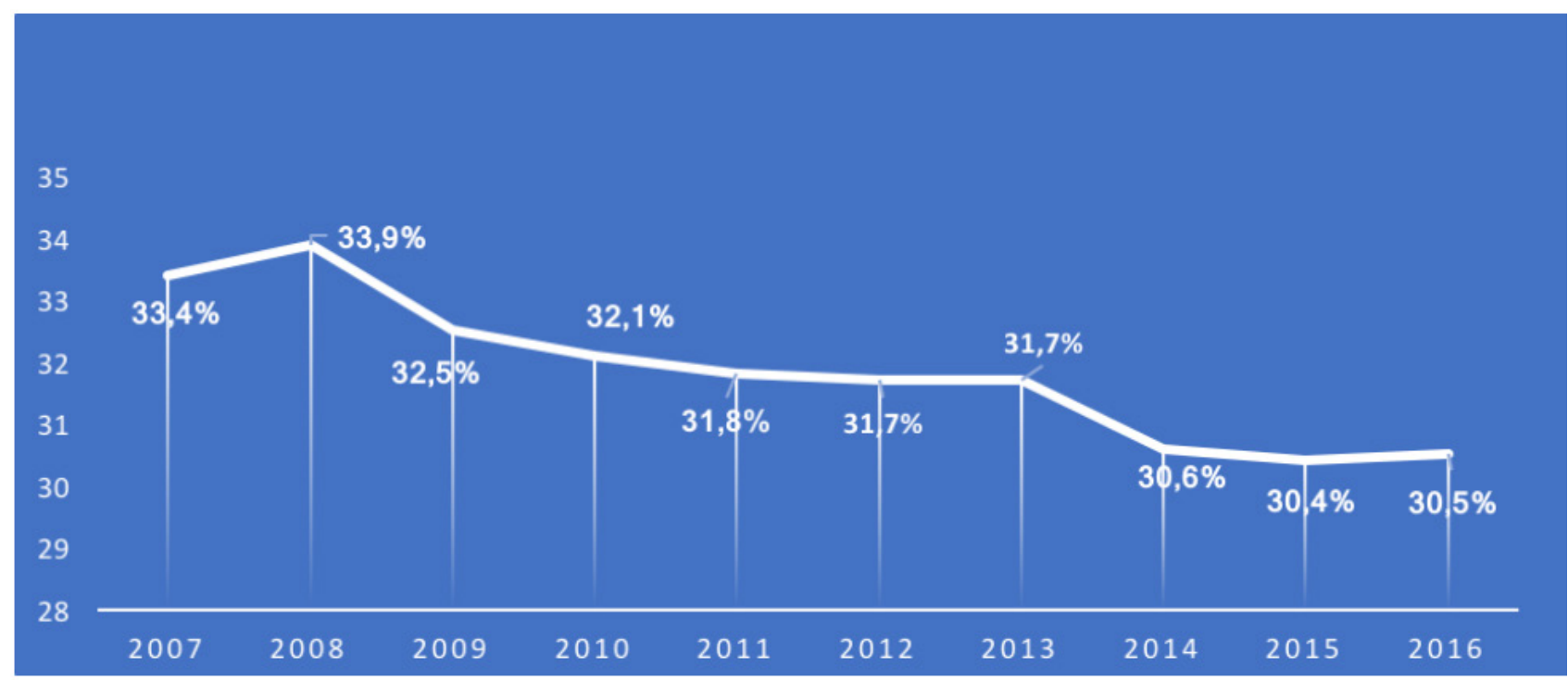

Fonte: Elaborado a partir de dados do Institut de la Statistique du Quebec (2017).

Pessoas analfabetas ou pouco escolarizadas têm chances menores de conseguir um trabalho. Em 2017, essas pessoas corresponderam a $45 \%$ dos beneficiários de auxílio social (MINISTÈRE DU TRAVAIL, DE L'EMPLOI ET DE LA SOLIDARITÉ SOCIALE, 2017). Segundo o Instituto de Estatísticas de Quebec, os empregos acessíveis às pessoas sem diploma estão em queda: eles passaram de 33,4\% em 2007 para 30,5\% em 2016.

A baixa escolaridade também produz consequências sociais tais como menor participação política, pouco envolvimento em atividades altruístas, baixo engajamento sociocultural (MÉNARD, 2009), conforme se apresenta no Gráfico 6, em seguida. 
Gráfico 6 - A diplomação e a participação cidadã

Percentagem do segmento da população que...

... vota

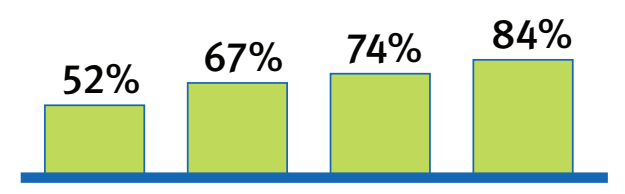

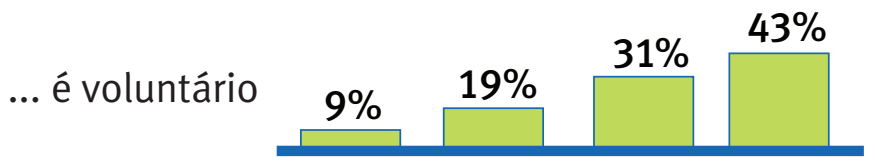

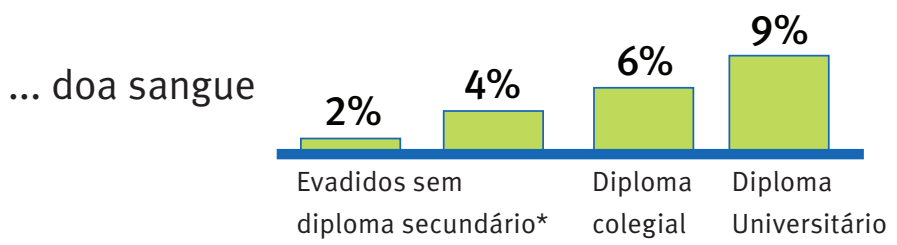

* Diploma de estudos secundários ou profissionais

Fonte: Journal of Public Economics; College Board; Mckinsey \& Compagnie

Fonte: Adaptado de Ménard (2009, p. 11).

Em 2001, o então ministro de Estado, Educação e Juventude François Legault lançou o Programme de formation de l'école québécoise para Educação Pré-escolar, Ensino Primário e Secundário. Esse programa tem por objetivo privilegiar uma aprendizagem adaptada à realidade dos jovens, assegurando o desenvolvimento de competências gerais essenciais, e valorizar os vínculos entre aprendizagem e os meios social e profissional. Ele convida os professores a modificarem a prática pedagógica visando o sucesso dos alunos. Ele propõe aos pais acompanhar a aprendizagem de seus filhos em casa e trabalhar em parceria com professores e outros membros da equipe escolar. As práticas pedagógicas foram repensadas visando adaptar o ensino ao ritmo dos alunos e às suas características, assegurando-lhes progresso contínuo (QUÉBEC, 2002b, 2006b).

Após a implantação do Programme de formation de l'école québécoise, diversos programas de combate à evasão escolar de jovens foram criados. Entre eles destacam-se Les services éducatifs complémentaires essentiales à réussite, Programme d'aide pour favoriser le retour en formation des 16-24 ans e o programa l'École, j’y tiens!

A análise das características e das necessidades dos alunos é essencial para a oferta de serviços educativos complementares adequados ao acompanhamento do percurso escolar discente. Esses serviços têm por objetivo 
propiciar "[...] o domínio de saberes essenciais, principalmente para alunos com dificuldades ou necessidades especiais aos quais o acompanhamento constante e apropriado evitará a exclusão” (QUÉBEC, 2002b, p. 11).

Com o intuito de aumentar a perseverança e o êxito de alunos com 16 anos ou mais, o Ministério da Educação, do Lazer e do Esporte de Quebec (Mels) adotou duas linhas de ação. A primeira diz respeito aos Serviços de Acolhida, Referência, Conselho e Acompanhamento (Sarca). Esse conjunto de serviços é destinado aos adultos matriculados na Formação Geral de Adultos ou em formação profissional que desejam receber orientações enquanto executam seus projetos profissionais ou formativos.

A segunda linha de ação é o programa de ajuda para favorecer o retorno de jovens entre 16 e 24 anos à formação. Destinado a jovens adultos com baixa escolaridade e em situação de evasão escolar, esse programa tem por objetivo oferecer a esses jovens a possibilidade de concluir a formação de base e se inserir profissionalmente (QUÉBEC, 2004a). Esse programa é realizado em parceria com as comissões escolares, os centros locais de emprego e outros centros de formação de jovens adultos, tais como os centros locais de serviços comunitários, os centros de juventude, os carrefour jeunesse-emploi - agências que fazem mediação entre jovens e ofertas de emprego (QUÉBEC, 2017).

Em 2003, o Mels, em parceria com a Universidade de Sherbrooke, realizou um levantamento de ambientes educacionais adaptados às necessidades de jovens adultos pouco escolarizados, de moradores de rua, desempregados, mães solteiras, de mulheres grávidas, etc. visando inspirar novas iniciativas. Os 11 ambientes considerados inspiradores são apresentados no Quadro 1, a seguir. 
Quadro 1 - Onze ambientes educacionais considerados inspiradores e adaptados às necessidades de jovens adultos pouco escolarizados

\begin{tabular}{|c|c|c|}
\hline Nome & Início & Objetivo \\
\hline $\begin{array}{l}\text { Le centre } \\
\text { L'intervalle }\end{array}$ & 1992 & $\begin{array}{l}\text { Reunir jovens de } 16 \text { a } 18 \text { anos em grupos personalizados, } \\
\text { com projeto pedagógicos diferenciado, oferecendo } \\
\text { orientação rigorosa e precisa, de modo a desenvolver } \\
\text { sentimento de pertencimento. }\end{array}$ \\
\hline $\begin{array}{l}\text { Le centre 16-18 } \\
\text { ans }\end{array}$ & 1995 & $\begin{array}{l}\text { Oferecer aos jovens um local de aprendizado adaptado e } \\
\text { diferente das escolas destinadas aos jovens e aos adultos. }\end{array}$ \\
\hline OVNI & 1995 & $\begin{array}{l}\text { Fornecer aos jovens evadidos uma possibilidade de } \\
\text { mudança para que eles saiam do isolamento, adquiram } \\
\text { gosto pela aprendizagem e reencontrem um projeto de vida. }\end{array}$ \\
\hline $\begin{array}{l}\text { Le Bon Dieu } \\
\text { dans la rue }\end{array}$ & 1997 & $\begin{array}{l}\text { Possibilitar aos jovens em situação de rua empreendeer um } \\
\text { processo de inserção social e retorno aos estudos. }\end{array}$ \\
\hline $\begin{array}{l}\text { Le } 16 \\
\text { D'abbotsford }\end{array}$ & 1998 & $\begin{array}{l}\text { Oferecer um serviço de formação mais direcionado e mais } \\
\text { adaptado às características de jovens entre } 16 \text { e } 18 \text { anos. }\end{array}$ \\
\hline $\begin{array}{l}\text { Stages en } \\
\text { entreprises } \\
\text { et projects } \\
\text { spéciaux }\end{array}$ & 1998 & $\begin{array}{l}\text { Oferecer iniciação profissional a jovens desmotivados a fim } \\
\text { de lhes possibilitar escolhas profissionais e envolvimento } \\
\text { com a comunidade. }\end{array}$ \\
\hline $\begin{array}{l}\text { Écola de la } \\
\text { rua Maison } \\
\text { Dauphine }\end{array}$ & 1999 & $\begin{array}{l}\text { Oferecer um ambiente educacional adaptado às } \\
\text { necessidades de jovens em situação de rua respeitando } \\
\text { seus valores e o ambiente de intervenção da Maison } \\
\text { Dauphine. }\end{array}$ \\
\hline $\begin{array}{l}\text { Project Ma } \\
\text { place au soleil }\end{array}$ & 2000 & $\begin{array}{l}\text { Tirar jovens mães do isolamento e da pobreza ajudando-as a } \\
\text { retomar os estudos secundários. }\end{array}$ \\
\hline $\begin{array}{l}\text { Les travailleurs } \\
\text { du patrimoine }\end{array}$ & 2001 & $\begin{array}{l}\text { Atender uma população distante do mercado de trabalho, } \\
\text { oferecendo-lhes experiências profissionais e, gradualmente, } \\
\text { despertando-lhes o gosto de retomar aos estudos. }\end{array}$ \\
\hline $\begin{array}{l}\text { Relance } \\
\text { scolaire }\end{array}$ & 2001 & $\begin{array}{l}\text { Acompanhar jovens tanto em sua tomada de decisão de } \\
\text { retomar os estudos como n escola visanto criar condições } \\
\text { favoráveis ao sucesso acadêmico. }\end{array}$ \\
\hline $\begin{array}{l}\text { Raccroche- } \\
\text { maman }\end{array}$ & 2002 & $\begin{array}{l}\text { Oferecer formação acessível e sob medida às jovens mães } \\
\text { para que elas possam retomar seus estudos. }\end{array}$ \\
\hline
\end{tabular}

Fonte: Elaborado a partir de dados disponibilizados em Québec (2004b).

De modo geral, os recursos destinados à manutenção dessas instituições são provenientes de Comissões escolares (setor de Formação Geral de Adultos), Fundo para a juventude, Emprego-Quebec, fontes de financiamento públicas e privadas, investimentos do Ministério da Educação no combate à evasão escolar, subsídios do Ministério do Emprego, da solidariedade social e da família, autofinanciamento, etc. 
Criado em 2009 pelo Mels, o programa l'École, j'y tiens! tem por objetivo prevenir, reduzir e combater a evasão escolar entre jovens adultos com menos de 20 anos. Ele considera que a evasão escolar não se refere somente ao aluno, sua família e à escola, mas também a diferentes atores, tais como: ministros de educação, professores, diretores de escolas, presidentes de comissões escolares, empregadores, etc. Por isso, ele convida cada um desses atores a exercer seu papel em favor do sucesso escolar.

Esse programa se apoia no princípio de que todos os alunos são capazes de “perseverar e conseguir". Para isso, ele “implanta práticas reconhecidas pela sua eficácia" e considera que "a perseverança e o sucesso escolares estão no centro das preocupações de muitos pesquisadores. As recomendações que eles emitem indicam pistas importantes para a elaboração de ações do governo de Quebec” (QUÉBEC, 2009, p. 4). Esse programa propõe 13 vias para atingir o sucesso escolar e expõe resultados obtidos por comissões escolares e escolas que reduziram as taxas de evasão após implantarem uma ou várias das seguintes vias:

\footnotetext{
1) valorizar a educação e a perseverança escolar em toda a província de Quebec; 2) estabelecer metas para cada comissão escolar e assegurar que elas sejam atingidas; 3) mobilizar os atores regionais; 4) preparar crianças de meios desfavorecidos ou em dificuldade para ingressarem na escola; 5) reduzir o número de alunos por turma no ensino primário; 6) reduzir os atrasos de aprendizagem no primário; 7) reforçar a estratégia de intervenção Agir de outro modo com base na ação de centenas de escolas; 8) oferecer acompanhamento individualizado aos alunos do secundário; 9) ampliar a oferta de atividades extraescolares esportivas e culturais; 10) realizar projetos comunitários visando jovens em risco de evadir do secundário, principalmente aqueles que residem nos bairros menos favorecidos de Montreal; 11) acompanhar melhor alunos do $4^{\circ}$ e $5^{\circ}$ anos do secundário para lhes conduzir à diplomação; 12) facilitar e encorajar o acesso à formação profissional; 13) recuperar o máximo de evadidas e evadidos (QUÉBEC, 2009, p. 12).
}

Entre as medidas implantadas pelo governo de Quebec, destacam-se o investimento anual de recursos financeiros, a redução do número de alunos por turma no Ensino Primário e nas escolas em meios menos favorecidos e a oferta de serviços de acompanhamento personalizado no secundário (QUÉBEC, 2009).

Apesar dos esforços empregados, em 2012 mais de 1 milhão de adultos (19\% da população de Quebec) na faixa etária de 16 a 65 anos tiveram baixos níveis de competência em leitura e letramento (nível <1 e 1 do Programa para Avaliação Internacional de Competências de Adultos - Peica) (RÉSEAU DE LUTTE À L'ANALPHABÉTISME, 2016). 


\section{CONSIDERAÇÕES}

A evasão escolar em Quebec resulta da confluência de um conjunto de fatores que interferem na vida dos alunos desde a infância e eclodem na adolescência. Esses fatores podem ser de natureza familiar, cultural, social, econômica ou uma combinação de diversos aspectos. Embora a maioria das pesquisas sobre esse tema tenha focalizado jovens entre 16 e 24 anos, em detrimento de adultos acima de 25 anos, o aumento do número de jovens matriculados na Formação Geral de Adultos sinaliza dois aspectos que merecem atenção: a mudança no perfil dos alunos dessa modalidade de ensino e a necessidade de fortalecer a perseverança desses jovens, evitando novas evasões e 0 abandono dos estudos.

Nota-se, por meio do exame dos programas de combate à evasão escolar implantados pelo governo de Quebec, que houve mais ênfase na prevenção e luta contra a evasão de jovens que de adultos. Entende-se que essa estratégia possa apresentar resultados positivos em médio e longo prazo. No entanto, a literatura consultada demonstrou que os filhos de pais pouco escolarizados tendem a se evadir mais frequentemente que seus pares cujos pais são mais escolarizados. Logo, uma das formas de reduzir a evasão escolar entre jovens é investir na formação de base dos adultos, salientando a importância da escola na formação cultural, política, filosófica e artística do ser humano. É igualmente importante investir na formação profissional possibilitando-lhes receber salários mais justos e prevenir a entrada precoce (antes do término dos estudos secundários) de seus filhos no mercado de trabalho. É também necessário haver políticas governamentais de geração de emprego e renda. Não apenas de empregos de baixa qualificação e baixos salários, mas empregos mais qualificados e mais bem remunerados.

Se a taxa de evasão escolar, em 2011-2012, foi de $24,2 \%$ entre jovens oriundos de meios menos favorecidos, importa fortalecer e ampliar políticas de combate à pobreza e à desigualdade social. A equidade e a justiça sociais passam pelo acesso, permanência e êxito no sistema educativo. Se nem todos chegam à escola com a mesma vivência social e cultural, deve-se assegurar o direito à educação e ao sucesso escolar, de acordo com as aspirações e o potencial de cada indivíduo (QUÉBEC, 2006c).

Os 11 ambientes educacionais considerados inspiradores sinalizam mudanças a serem realizadas na educação formal, por meio da adequação de espaços 
e práticas pedagógicas às necessidades formativas de jovens e adultos evadidos, da garantia de acesso ao conhecimento e à formação profissional visando à educação plena e ao exercício da cidadania.

Após a reforma instituída pelo Programme de formation de l'école québécoise, o currículo escolar foi organizado por competências, do maternal ao secundário. Essa mudança curricular teve por justificativa a necessidade de oferecer aos jovens uma formação que responda aos imperativos de uma sociedade em constante transformação. Sustentou-se igualmente que a escola não é o único meio pelo qual se podem adquirir conhecimentos, que o aluno pode aprender de diversas formas e usando vários recursos, em particular as novas tecnologias de informação e comunicação. No Ensino Secundário, especialmente no segundo ciclo, os objetivos a serem alcançados compreendem o desenvolvimento da empregabilidade pela aquisição de competências, de conhecimentos e de atitudes gerais e específicas necessárias para ingressar e manter-se no mercado de trabalho. Ou seja, o saber fazer, saber operacional, pragmático, voltado à solução de problemas, que destitui os jovens trabalhadores dos elementos intelectuais do trabalho, dos seus fundamentos teóricos - científicos e tecnológicos -, promotores da autonomia intelectual, da capacidade de reagir às mudanças no mundo do trabalho, etc.

A organização do currículo por competências nos sugere um paralelo com o contexto brasileiro. Ainda que as políticas educacionais no Brasil sejam elaboradas conforme os acordos internacionais dos quais o País é signatário, os programas de formação profissional, implantados a partir de 2011, e a reforma curricular do Ensino Médio, em andamento desde 2016, indicam o alinhamento do Brasil à teoria do capital humano que se inspira em países industrializados da América do Norte e da Europa. Essa teoria, baseada na relação direta entre educação escolar e empregabilidade, reduz o currículo a uma série de competências a desenvolver.

Os empregos qualificados exigem uma formação ampla e durável à qual os trabalhadores pouco escolarizados não têm acesso (POCHMANN; FERREIRA, 2016). No Brasil, essa formação é realizada em cursos técnicos integrados ao Ensino Médio oferecidos pela Rede Federal de Educação Profissional, Científica e Tecnológica. Reconhecida por sua excelência, a rede federal possui processos seletivos rigorosos, infraestrutura de qualidade (prédios e laboratórios), equipe de profissionais selecionados em concursos públicos, professores detentores de experiência técnica e formação universitária. 
Em Quebec, esse tipo de formação ocorre nos Collège d’Enseignement Général et Professionnel (Colégios de ensino geral e profissional - Cégeps). Os Cégeps são instituições públicas de ensino superior que oferecem formação técnica semelhante à graduação tecnológica no Brasil, cursos preparatórios para ingresso em nove grandes áreas de estudos universitários e cursos de formação continuada voltados à qualificação profissional (FEDERATION DES CEGEPS, 2018). Os Cégeps possuem processos seletivos concorridos, excelentes acomodações, laboratórios bem equipados, professores e equipe pedagógica de qualidade.

Os alunos da Educação de Jovens e Adultos (EJA) no Brasil, bem como os estudantes da Formação Geral de Adultos em Quebec, são os mais penalizados pela formação orientada unicamente por interesses econômicos. Isso se deve ao fato de que eles não possuem educação de base que lhes possibilite progredir nos estudos, seja seguindo um curso técnico ou ingressando no ensino superior. Consequentemente, não poderão receber melhores salários devido às funções semiespecializadas que exercem (POCHMANN; FERREIRA, 2016; QUÉBEC, 2006c). Entende-se que a educação desvinculada de políticas de geração de emprego não é capaz de assegurar inserção profissional. Porém, a ausência dela representa enorme obstáculo para aqueles que desejam conseguir trabalho formal.

Os adultos sem educação de base suficiente têm mais dificuldade em manter seus filhos na escola até a obtenção do diploma de estudos secundários, por causa dos baixos salários e da falta de recursos para assegurar as condições de sucesso escolar. Esses jovens valorizam mais o acesso ao mercado de trabalho que a perseverança nos estudos, pois, para eles, o trabalho é uma fonte de satisfação de suas aspirações e necessidades de curto prazo, bem como de seus filhos. No entanto, eles parecem desconhecer os inconvenientes e os efeitos negativos que essa escolha acarreta em médio e longo prazo. 


\section{School dropout in Secondary Education in Quebec (Canada)}

Abstract: Among Canadian provinces, Quebec has the highest rate of youths without a secondary education degree, i.e., $11.5 \%$ in 2016 . The study aimed to: a) examine the profile of these youths and map the reasons why they did not complete their course of study; b) analyze the extent to which government programs implemented to prevent and fight school dropout are effective and equitable. A bibliographic research was conducted with the Scopus, Eric and Érudit databases. Official publications of the Quebec government were also examined. School dropout was found to be higher: among males than among females; in the public education system (18.4\%) than in the private system (7.6\%). In schools in Indian reserves, dropout rates reach $81.3 \%$. Parental lack of education is among the main causes of school dropout.

Keywords: School dropout in Quebec. Youths and adults. Secondary education. 


\section{Abandono escolar en la Enseñanza Secundaria en Quebec (Canadá)}

Resumen: Entre las provincias canadienses, Quebec posee la tasa más alta de jóvenes no graduados en secundaria, con un 11,5 \% en 2016. La investigación realizada tuvo como objetivo: a) examinar el perfil de estos jóvenes y localizar los motivos por los cuales no habían concluido los estudios; b) analizar en qué medida los programas gubernamentales implantados para prevenir y combatir el abandono escolar son eficaces y equitativos. Se realizó una investigación bibliográfica en las bases de datos Scopus, Eric y Érudit. Se consultaron también publicaciones oficiales del Gobierno de Quebec. Se comprobó que el abandono es mayor entre hombres que entre mujeres, y en la red pública de enseñanza (18,4 \%) que en la red privada (7,6 \%). En las escuelas de las reservas indias llega al 81,3\%. La baja escolaridad de los padres está entre las principales causas de abandono.

Palabras clave: Abandono escolar en Quebec. Jóvenes y adultos. Enseñanza secundaria. 


\section{REFERÊNCIAS}

BARIL, Daniel. Financement de l'éducation des adultes: situation dramatique pour des organisations en éducation des adultes financées par le gouvernement fédéral. Montreal: Icea, 8 nov. 2017. Disponível em: 〈http://icea.qc.ca/site/ fr/actualites/financement-de-1\%E2\%80\%99\%C3\%A9ducation-des-adultessituation-dramatique-pour-des-organisations-en». Acesso em: 3 nov. 2017.

BARRIAULT, Lucie. Les conséquences économiques du décrochage scolaire. Québec: PRÉCA, 2016. 14 p. Disponível em: 〈http://www.ctreq.qc.ca/wpcontent/uploads/2016/05/Feuillet-de-sensibilisation_WEB.pdf〉. Acesso em: 1 set. 2017.

BLAYA, Catherine; FORTIN, Laurir. Les élèves français et québécois à risque de décrochage scolaire: comparaison entre les facteurs de risque personnels, familiaux et scolaires. L'orientation scolaire et professionnelle, v. 40, n. 1, p. 1-26, mars 2011. Disponível em: 〈http://osp.revues.org/2988〉. Acesso em: 14 nov. 2017.

BRASIL. Ministério da Educação. Inep. Indicadores de fluxo escolar da educação básica. Brasília, DF, jun. 2017.13 slides: color. Disponível em: «http:// download.inep.gov.br/educacao_basica/censo_escolar/apresentacao/2017/ apresentacao_indicadores_de_fluxo_escolar_da_educacao_basica.pdf $\rangle$. Acesso em: 7 ago. 2018.

BUSHNIK, Tracey. Étudier, travailler et décrocher: relation entre le travail pendant les études secondaires et le décrochage. Document de Recherche, Otawa, Statistique Canada, n. 81-595-MIF2003004, p. 1-39, 2003. Disponível em: 〈http://www.publications.gc.ca/Collection/Statcan/81-595-MIF/81-595MIF2003004.pdf> Acesso em: 1 set. 2017.

DORAY, Pierre; BÉLANGER, Paul. Retirer à Pierrette pour donner à Alexandre! Le développement de la formation générale des adultes au Québec. Revue des sciences de l'éducation, Québec, v. 40, n. 2, p. 215-251, 2014. Disponível em: 〈https://www.erudit.org/fr/revues/rse/2014-v40-n2-rse01681/1028420ar/〉. Acesso em: 14 nov. 2017.

FEDERATION DES CEGEPS. Qu'est-ce qu'un cégep. 2018. Disponível em: 〈http://www.fedecegeps.qc.ca/cegeps/qu-est-ce-qu-un-cegep/〉. Acesso em: 6 ago. 2018. 
FRANCO, Maria Ciavatta. Quando nós somos o outro: questões teóricometodológicas sobre os estudos comparados. Educação \& Sociedade, ano XXI, n. 72, p. 197-230, ago. 2000. Disponível em: 〈http://www.scielo.br/ pdf/\%0D/es/v21n72/4200.pdf $\rangle$. Acesso em: 6 ago. 2018.

GILLES, Jean-Luc; CHRISTINAT, Chantal Tièche; DELÉVAUX, Olivier. Origines, fondements et perspectives offertes par les alliances éducatives dans la lutte contre le décrochage scolaire. In: GILLES, Jean-Luc; POTVIN, Pierre; CHRISTINAT, Chantal Tièche. (Org.) Les alliances educatives pour lutter contre le décrochage scolaire. Berne, Suisse: Peter Lang, 2012. p. 3-18.

GILMORE, Jason. Tendances du taux de décrochage et des résultats sur le marché du travail des jeunes décrocheurs. Statistique Canada, v. 7, n. 4, 2010. Disponivel em: 〈https://www150.statcan.gc.ca/n1/pub/81-004-x/2010004/ article/11339-fra.htm>. Acesso em: 15 out. 2017.

GOROSTIAGA, Jorge. Un abordage de la cuestión epistemológica en los estudios comparados sobre política educativa. In: TELLO, César (Org.). Epistemologías de la política educativa: posicionamientos, perspectivas y enfoques. Campinas: Mercado de Letras, 2013. p. 239-267.

INSTITUT DE COOPERATION POUR L'EDUCATION DES ADULTES. Donner un nouveau souffle à l'éducation des adultes au Québec: exposé des conjonctures externe et interne accompagnant la proposition de planification stratégique pluriannuelle 2016-2021. Québec, Icea: 2016a. Disponível em: 〈http:// icea.qc.ca/site/sites/default/files/planification_strategique_de_licea_-_ document_de_reflexion_.pdf $\gg$. Acesso em: 6 set. 2017.

INSTITUT DE COOPERATION POUR L'EDUCATION DES ADULTES. Donner un nouveau souffle à l'éducation des adultes au Québec: déclaration politique de l’Icéa. Québec, 2016b. Disponível em: 〈http://icea.qc.ca/site/sites/default/ files/icea-declaration_politique.pdf〉. Acesso em: 6 set. 2017.

INSTITUT DE LA STATISTIQUE DU QUEBEC. Indicateurs du marché du travail, résultats selon le niveau de scolarité et le sexe, Québec, Ontario et Canada. Québec, 2017, 2 p. Disponível em: 〈http://www.stat.gouv.qc.ca/statistiques/ travail-remuneration/population-active-chomage/indicateur-marche/emploi_ taux.html>. Acesso em: 15 out. 2017.

INSTITUTO BRASILEIRO DE GEOGRAFIA E ESTATÍsTICA. Pesquisa Nacional por Amostra de Domicílios Contínua. Rio de Janeiro: IBGE, 2017. 12 p. Disponível em: 〈https://biblioteca.ibge.gov.br/visualizacao/livros/liv101576_ informativo.pdf». Acesso em: 6 ago. 2018. 
JANOSZ, Michel. L'abandon scolaire chez les adolescents: perspective nordaméricaine VEI Enjeux, n. 122, p. 104-127, sep. 2000. Disponível em: «https:// www.researchgate.net/publication/228643494_L\%27abandon_scolaire_ chez_les_adolescents_perspective_nord-americainè. Acesso em: 15 out. 2017.

et al. Les élèves du primaire à risque de décrocher au secondaire: caractéristiques à 12 ans et prédicteurs. Institut de la statistique du Québec, v. 7, n. 2, p. 1-22, fev. 2013. Disponível em: 〈http://www.stat.gouv.qc.ca/ statistiques/education/frequentation-scolaire/decrochage.pdf $\rangle$. Acesso em: 6 set. 2017.

LANGEVIN, Louise. L'abandon scolaire: on ne naît pas décrocheur! 2. ed. Laval: Les Éditions Logiques, 1999.

LECLERC, Danielle; POTVIN, Pierre; MASSÉ, Line. Perception du type d'élève, du cheminement anticipé, de l'attitude des enseignants à la maternelle, première année, deuxième année et qualification des élèves à la fin du secondaire: diplomation ou décrochage? Revue de psychoéducation, v. 45, n. 1, p. 113130, 2016. Disponível em: 〈http://www.pierrepotvin.com/6.\%20Publications/ VOL45N01_113-130_LECLERC.pdf〉. Acesso em: 15 out. 2017.

L'OBSERVATOIRE DE L'ADMINISTRATION PUBLIQUE. Les trois réseaux de l'éducation. L'état québécois en perspective. 2012. Disponível em: 〈http:// cerberus.enap.ca/Observatoire/docs/Etat_quebecois/a-education1.pdf〉. Acesso em: 6 set. 2017.

MAZALONS, Élisabeth; BOURDON, Sylvain. Les choix scolaires et les obstacles à la participation des jeunes adultes non diplômés inscrits en formation professionnelle. In: VILLEMAGNE, Carine; MYRE-BISAILLON, Julie. (Org.). Les jeunes adultes faiblement scolarisés: parcours de formation et besoins d'accompagnement. Québec: Presses de l'Université du Québec, 2015. p. 165-184.

MÉNARD, Jacques. Savoir pour pouvoir: entreprendre un chantier national pour la persévérance scolaire. Montréal: Groupe d’action sur la persévérance et la réussite scolaires au Québec, 2009. Disponível em: 〈https://www.bmo. com/bmo/files/images/4/2/Savoirpourpouvoir.pdf . Acesso em: 6 set. 2017.

MINISTĖRE DU TRAVAIL, DE L'EMPLOI ET DE LA SOLIDARITÉ SOCIALE. Rapport statistique sur les clientèles des programmes d'assistance sociale. Tableau 3. Québec, août 2017. p. 5-6. Disponível em: 〈https://www.mtess.gouv.qc.ca/ publications/pdf/MTESS_stats-AS_2017-08.pdf〉. Acesso em: 15 out. 2017. 
ORGANIZAÇÃO DAS NAÇÕES UNIDAS PARA A EDUCAÇÃO, A CIÊNCIA E A CULTURA. Rapport final. Forum mondial sur l'éducation. Dakar, Sénégal, 2000a. Disponível em: 〈http://unesdoc.unesco.org/images/0012/001211/121117f. pdf〉. Acesso em: 6 set. 2017.

- Cadre d'action de Dakar. Forum mondial sur l'éducation. Dakar, Sénégal, 2000b. Disponível em: 〈http://unesdoc.unesco.org/ images/0012/001211/121147f.pdf〉. Acesso em: 6 set. 2017.

PICA, Lucille; PLANTE, Nathalie; TRAORÉ, Issouf. Décrochage scolaire chez les élèves du secondaire du Québec, santé physique et mentale et adaptation sociale: une analyse des principaux facteurs associés. Zoom Santé, Montréal, Institut de la statistique du Québec, n. 46, p. 1-20, set. 2014. Disponível em: $\quad$ http://www.stat.gouv.qc.ca/statistiques/sante/bulletins/zoomsante-201409.pdf>. Acesso em: 6 set. 2017.

POCHMANN, Marcio; FERREIRA, Eliza Bartolozzi. Escolarização de jovens e igualdade no exercício do direito à educação no Brasil: embates do início do século XXI. Educação \& Sociedade, Campinas, v. 37, n. 137, p. 1241-1267, out./dez. 2016. Disponível em: 〈http://www.scielo.br/pdf/es/v37n137/16784626-es-37-137-01241.pdf〉. Acesso em: 8 ago. 2018.

POTVIN, Pierre. Le décrochage scolaire: dépistage et intervention. Les cahiers dynamiques, n. 65, p. 50-57, 2015. Disponível em: 〈http://www.pierrepotvin. com/6.\%20Publications/D\%C3\%A9crochage\%20scolaire.pdf〉. Acesso em: 6 set. 2017.

QUÉBEC. Ministère de l'Éducation. Plan d'action en matière d'éducation des adultes et de formation continue. Montreal, 2002a. 40 p. Disponível em: 〈http://www.education.gouv.qc.ca/fileadmin/site_web/documents/ publications/Plan.pdf〉. Acesso em: 14 nov. 2017.

Les services éducatifs complémentaires essentiales à réussite. Montreal, 2002b. 59 p. Disponível em: 〈http://www.education.gouv. qc.ca/fileadmin/site_web/documents/dpse/adaptation_serv_compl/SEC_ Services_19-7029_.pdf〉. Acesso em: 14 nov. 2017.

- Programme d'aide pour favoriser le retour en formation des 16-24 ans. Cahier de mise en œuvre. Montreal, 2004a. 26 p. Disponível em: «http:// www.education.gouv.qc.ca/fileadmin/site_web/documents/dpse/educ_ adulte_action_comm/miseenoeuvre.pdf ».Acesso em: 15 out. 2017. 
Programme d'aide pour favoriser le retour en formation des 16-24 ans. Fiches descriptives. Montreal, 2004b. 50 p. Disponível em: 〈http://www. education.gouv.qc.ca/fileadmin/site_web/documents/dpse/educ_adulte_ action_comm/fichesdescriptives.pdf〉. Acesso em: 15 out. 2017.

. Ministère de l’Éducation, du Loisir et du Sport. L’Éducation au Québec en bref. Montreal, 2006a. 10 p. Disponível em: 〈http://www.education.gouv. qc.ca/fileadmin/site_web/documents/dpse/educ_adulte_action_comm/ educqcfra.pdf $\rangle$. Acesso em: 6 maio 2017.

Programme de formation de l'école québécoise. Éducation préscolaire. Enseignement primaire. Montreal, 2006b. 364 p. Disponível em: 〈http://www.education.gouv.qc.ca/fileadmin/site_web/documents/dpse/ formation_jeunes/prform2001.pdf〉. Acesso em: 3 nov. 2017.

. Conseil Supérieur de l'Éducation. En éducation des adultes, agir sur l'expression de la demande de formation: une question d'équité. Montreal, 2006c. 75 p. Disponível em: 〈https://www.cse.gouv.qc.ca/fichiers/ documents/publications/Avis/50-0450.pdf〉. Acesso em: 7 set. 2017.

Une histoire de l'éducation des adultes. Montreal, 2007a. 125 p. Disponível em: 〈http://www.education.gouv.qc.ca/fileadmin/site_web/ documents/dpse/educ_adulte_action_comm/41-7018.pdf . Acesso em: 15 out. 2017.

. Décrochage et retard scolaires. Caractéristiques des élèves à l'âge de 15 ans. Analyse des données québécoises recueillies dans le cadre du projet Pisa/Ejet. Montreal, 2007b. 72 p. Disponível em: 〈http://www.education.gouv. qc.ca/fileadmin/site_web/documents/publications/DecroRetardScolRapport. pdf . Acesso em: 7 set. 2017.

. L'école, j’y tiens! Tous ensemble pour la réussite scolaire. Montreal, 2009. 33 p. Disponível em: 〈http://www.education.gouv.qc.ca/fileadmin/site_ web/documents/dpse/formation_jeunes/LEcoleJyTiens_TousEnsemblePourL aReussiteScolaire.pdf ». Acesso em: 15 out. 2017.

Ministère de l'Éducation et de l'Enseignement Supérieur. Statistiques de l'éducation. Éducation préscolaire, enseignement primaire et secondaire. Montreal, 2015a. 126 p. Disponível em: 〈http://www.education. gouv.qc.ca/fileadmin/site_web/documents/PSG/statistiques_info_ decisionnelle/15-00503_statistiques_2015_edition_v25oct.pdf〉. Acesso em: 6 set. 2017. 
. Les décrocheurs annuels des écoles secondaires du Québec. Bulletin statistique de l'éducation, Québec, n. 43, p. 1-24, maio 2015b. Disponível em: 〈http://www.education.gouv.qc.ca/fileadmin/site_web/documents/PSG/ statistiques_info_decisionnelle/BulletinStatistique43_f.pdf $>$. Acesso em: 3 nov. 2017.

- Ministère de l'Éducation, du Loisir et du Sport. Taux de sorties sans diplôme ni qualification (décrochage annuel), parmi les sortants, en formation générale des jeunes, selon le sexe, par réseau d'enseignement et par commission scolaire, 2013-2014 (2015c). Disponível em: «http://www. education.gouv.qc.ca/fileadmin/site_web/documents/PSG/statistiques_ info_decisionnelle/Tableau_taux-officiels-decrochage_CS_2013-2014.pdf >. Acesso em: 3 nov. 2017.

. Taux de décrochage annuel au secondaire, 1999-2015. Québec, 2016. Disponivel em: 〈http://www.education.gouv.qc.ca/references/publications/ resultats-de-la-recherche/detail/article/taux-de-decrochage-annuel/>. Acesso em: 15 out. 2017.

. Formation des adultes. Québec, 2017. Disponível em: 〈http://www. education.gouv.qc.ca/enseignants/dossiers/formation-des-adultes/〉. Acesso em: 15 out. 2017.

. Indice de milieu socio-économique. Québec, 2018. Disponível em:

〈http://www.education.gouv.qc.ca/enseignants/aide-et-soutien/milieuxdefavorises/agir-autrement/indice-de-milieu-socio-economique-imse/>. Acesso em: 7 ago. 2018.

QUÉBEC. Loi sur l'instruction publique. Atualizada em abril de 2017. Disponível em: 〈http://www.legisquebec.gouv.qc.ca/fr/ShowDoc/cs/I-13.3〉. Acesso em: 15 out. 2017.

RÉSEAU DE LUTTE A L'ANALPHABÉTISME. Pour une stratégie nationale de lutte à l'analphabétisme. Québec, 2016. 24 p. Disponível em: <http:// lutteanalphabetisme.ca/wp-content/uploads/2016/05/PlateformeR\%C3\%A9seau-de-lutte-\%C3\%A0-lanalphab\%C3\%A9tisme-VFc.pdf . Acesso em: 6 set. 2017.

ROBERT, Paul; REY-DEBOVE, Josette; REY, Alain. Décrochage. In: . Le Petit Robert: dictionnaire alphabétique et analogique de la langue française. Paris: Le Robert, 2012. 
SILVA FILHO, Raimundo Barbosa; ARAÚJO, Ronaldo Marcos de Lima. Evasão e abandono escolar na educação básica no Brasil: fatores, causas e possíveis consequências. Educação por escrito, Porto Alegre, v. 8, n. 1, p. 35-48, jan./ jun. 2017. Disponível em: 〈http://revistaseletronicas.pucrs.br/ojs/index.php/ porescrito/article/download/24527/15729〉. Acesso em: 6 ago. 2018.

STATISTIQUE CANADA. Profil du recensement, Recensement de 2016. Otawa: Statistique Canada, 8 fev. 2017. Disponível em: 〈https://www12.statcan. gc.ca/census-recensement/2016/dp-pd/prof/index.cfm?Lang=F〉. Acesso em: 30 ago. 2017.

UPPAL, Sharanjit. Les jeunes hommes et les jeunes femmes sans diplôme d'études secondaires. Regards sur la société canadienne, n. 75-006-X, maio 2017. Disponivel em: 〈http://www.statcan.gc.ca/pub/75-006-x/2017001/ article/14824-fra.pdf $>$. Acesso em: 6 set. 2017.

\section{SOBRE OS AUTORES}

Sandra Maria Glória da Silva é doutoranda em Educação na Universidade de São Paulo.

E-mail: sandragloria@usp.br.

Pierre Canisius Kamanzi é professor adjunto na Faculdade de Ciências da Educação da Université de Montréal.

E-mail: pierre.canisius.kamanzi@umontreal.ca.

Recebido em: julho de 2018

Aprovado em: agosto de 2018 